* Renato Bernardi- Doutor em Direito do Estado pela PUC-SP, professor dos cursos de pós graduação latu sensu,PROJURIS das Faculdades Integradas de Ourinhos - FIO, professor efetivo do curso de PósGraduação stricto sensu Mestrado - e do curso de graduação da Faculdade de Direito do Centro de Ciências Sociais Aplicadas da Universidade Estadual do Norte do Paraná - UENP. É procurador do Estado de São Paulo desde 1994. Email: bernardi@uenp. edu.br

** Mestranda em Ciências Jurídicas pela UENP, especialista em Direito do Trabalho pela CESUMAR, professora de Direito do Trabalho e Processo do Trabalho na PUC-PR campus Londrina. E-mail: raquel@ capobiango.adv.br

\section{As garantias constitucionais à igualdade de gênero e a realidade do "teto de vidro" para a mulher trabalhadora}

\author{
CONSTITUTIONAL GUARANTEES TO GENDER \\ EQUALITY AND THE REALITY "GLASS CEILING" \\ FOR WOMEN WORKING \\ * Renato Bernardi \\ ** Raquel Cristina Neves
}

Resumo: No presente artigo faz-se uma avaliação da distinção de gêneros e a preponderância do papel masculino no mercado de trabalho ao longo da história. Analisa-se o quadro legislativo existente antes da promulgação da Constituição Federal de 1988 e, posteriormente à sua edição a adoção de medidas coibitivas à discriminação de gênero especificamente sobre a discriminação contra a mulher no ambiente de trabalho. Busca-se a compreensão das diversas formas de discriminação e analisa-se a igualdade que se deseja alcançar nos dias atuais. São apresentados os números representativos do comportamento do mercado de trabalho para a mulher em dados estatísticos do IBGE. Tais dados servem para corroborar a existência do fenômeno do "teto de vidro”, ou seja, a linha imaginária que impede a ascensão da mulher a cargos hierárquica e economicamente superiores, cargos de mando. Conclui-se, por fim, pela necessidade de romper tais limites através de adoção de medidas que coíbam os empregadores de manter promoções voltadas ao critério gênero.

Palavras-chave: Mulher. Trabalhadora. Igualdade. Teto de vidro.

Abstract: This article presents a review of gender distinction and the preponderance of male role in the labor market throughout history. Analyzes the existing legislative framework before the enactment of the Federal Constitution of 1988 and, after its edition the adoption of prohibitive measures to gender discrimination specifically on discrimination against women in the workplace. Search to understand the various forms of discrimination and analyzes the equality to be reached today. Representative numbers of labor market behavior for women in statistics from the IBGE are presented. These data serve to corroborate the existence of the phenomenon of the "glass ceiling", i.e. the imaginary line that prevents the rise of women to senior positions hierarchically and economically, command positions. The conclusion, finally, the need to break those limits through adoption of measures that restrain employers to maintain promotions aimed at gender criteria.

Keywords: Woman. Working. Equality. Glass ceiling. 


\section{INTRODUÇÃO}

A chamada Constituição Cidadã, completou em outubro do presente ano, 25 anos. Símbolo de um Estado de Direito que realçou valores de justiça, liberdade e igualdade contra qualquer tipo de discriminação, trouxe para as mulheres o reconhecimento da igualdade em relação aos homens.

Com base neste preceito, analisa-se a crescente participação das mulheres no mercado de trabalho formulando um questionamento: se a igualdade de tratamento que foi elevada a preceito constitucional, constituindo, pois, um direito fundamental das mulheres vem sendo assegurada na prática.

Para a mulher ingressar no mercado de trabalho hodiernamente, cederam todas as barreiras impeditivas, limitativas ou proibitivas, no entanto, isto não tem evitado a adoção de práticas discriminatórias quando se trata de permitir a ascensão profissional.

A mulher se multiplica para conseguir demonstrar que pode tanto quanto os homens manter-se no mercado de trabalho, manter-se na vida acadêmica, sem deixar de cumprir com afazeres domésticos, sem deixar de cuidar de filhos e marido, no entanto, não é sem restrições que transita no ambiente laboral.

Ainda que no campo da economia se verifique que muitos lares são sustentados por mulheres, não se lhes reconhece o direito aos mesmos salários que são pagos aos homens.

Neste sentido é necessário reconhecer que, muito embora tenha havido progressos estes são insuficientes para assegurar uma efetiva igualdade, sendo necessário analisar e repensar medidas para se romper a última barreira à igualdade feminina no local de trabalho - o "teto de vidro".

\section{A QUESTÃO GÊNERO}

Diferenças de gênero talvez tenham sido os primeiros ensaios do homem à compreensão das desigualdades no convívio social. O homem das cavernas, preocupado com a garantia da espécie, segregou o grupo tomando os mais fortes, assim fisicamente considerados, para a atividade da caça e, por consequência, alimentação do grupo, deixando aos mais fracos o cuidado com a prole e com o próprio meio em que viviam. Certamente não havia ainda os anseios decorrentes de acúmulos de riquezas, não havia o estranhamento das diferenças de cores, a alma, as implicações religiosas e filosóficas não eram importantes à medida que se buscava meramente a sobrevivência no ambiente hostil. 
A escritora e política ALEMBERT (2004, p. 27-28) em sua obra esclarece que feminino e o masculino se complementavam e viviam agregados para assegurar a sobrevivência, assim, o primeiro passo, na evolução da sociedade humana, aconteceu a partir da formação das genes comunitárias, que se constituíam de grandes uniões de grupos humanos vinculados por parentesco, que se dividiram em clãs. Nesse tipo de organização, a mulher trabalhava a terra, domesticava animais, cuidava das crianças, dos velhos e dos doentes, além de criar vasilhames, utilizar o fogo, preparar unguentos, poções, enquanto o homem ia à caça de alimentos.

Para o gênero masculino tudo era conquista: caça, território, poder, sexo, fêmeas, crias.

Para o gênero feminino tudo era aceitação e subserviência.

É claro que a história também dá conta de algumas sociedades primitivas focadas no poder feminino; a antropóloga americana MEAD (1978, p. 131132), escreveu em 1928 “Adolescência, Sexo e Cultura em Samoa”, apontando, entre outros aspectos a existência de sociedades em que não é possível fazer as tradicionais distinções de gênero, identificando, diferenças culturais muito antes do que biológicas entre homens e mulheres.

A relevância do estudo de Mead está na compreensão de que as diferenças entre homens e mulheres encontram-se num campo simbólico, na produção cultural de cada sociedade em determinada época e local, não em características físicas ou biológicas. Sendo que cada qual desempenha papéis e funções de acordo com as regras que prevalecem na sociedade na qual estão inseridos e num dado contexto histórico.

Porém, nossa sociedade desenvolveu-se principalmente em conformidade com a cultura judaico-cristã que catapultou a figura masculina como dominante e a feminina, considerando os reclamos da maternidade, à submissão.

Neste quadro é, portanto, possível concluir que o primeiro discriminen humano foi utilizado para identificar fortes e fracos, estando, obviamente, a mulher "catalogada” no segundo grupo.

Não se vai aqui traçar uma retrospectiva histórica da evolução do papel da mulher ao longo desta evolução, apenas é necessário traçar este marco inicial para situar o ponto de partida da posição feminina no trabalho para se chegar aos dias atuais de modo a se analisar o que é conquista e, portanto ganho efetivo, e o que é ainda resquício da discriminação histórica. 


\section{O PANORAMA DO TRABALHO DA MULHER NO BRASIL DA CONSTITUIÇÃO FEDERAL DE 1988}

A assembleia constituinte de 1988 trouxe ganhos efetivos à causa feminista, porém, algumas leis anteriores já haviam avançado em termos de sociedade patriarcal exclusivista, porém, com propósitos.

Historicamente a mulher teve que lutar para alcançar inúmeros direitos, os mais comezinhos que hoje sequer parece possível imaginar que possam nos ter sido negados por longos anos, como o direito ao voto (assegurado no Brasil por Getúlio Vargas em 1932), direito de trabalhar sem necessidade de autorização do marido (Estatuto da Mulher Casada - 1962), igualdade de direitos entre homens e mulheres (Carta das Nações Unidas de 1945).

Aos olhos dos mais jovens não parece possível que um artigo de lei do trabalho contasse com a redação tal qual era a do art. 446 paragrafo único da CLT que dizia:

Ao marido ou pai é facultado pleitear a rescisão do contrato de trabalho [da mulher], quando a sua continuação for suscetível de acarretar ameaça aos vínculos da família, perigo manifesto às condições peculiares da mulher ou prejuízo de ordem física ou moral para o menor.

O papel da mulher era, pois, principalmente, o de uma célula mater, a parideira que tem se dedicar única e exclusivamente a arte da maternidade e das boas prendas do lar e, se em último caso se aventurar no mercado de trabalho deve ser protegida contra toda forma de abuso de modo a limitar, limitar e limitar sua possibilidade de entrar em concorrência com os homens.

Neste panorama, até o advento da Constituição de 1988, com as conquistas de todos os trabalhadores numa sociedade pós Revolução Industrial, em que se buscou impedir a exploração absurda da mão de obra, mormente a infantil e a da mulher, o Brasil e o mundo se preocuparam em dar feições ilusoriamente protetivas ao trabalho da mulher.

Necessário esclarecer porque afirmar que as medidas eram ilusoriamente protetivas através da análise de BRUSCHINI e LOMBARDI (2000, p. 323) sobre o mercado de trabalho na época:

Voltando a analisar as demais posições na ocupação dos trabalhadores, nota-se que a inserção das mulheres no mercado de trabalho brasileiro tem sido caracteriza através do tempo pela marca da precariedade que tem atingido 
uma importante parcela de trabalhadoras. Mesmo que os dados sinalizem um decréscimo relativo desse contingente na década de 1990, ainda assim, em 1998, nada mesmo que 36\% da força de trabalho feminina ou 10 milhões de mulheres situavam-se em nichos precários do mercado de trabalho, seja como trabalhadoras domésticas, seja realizando atividades não remuneradas ou trabalhos destinados ao consumo próprio ou do grupo familiar.

Assim, a legislação assegurava proteção, porém, grande parte do trabalho feminino precarizado estava à margem da legislação.

Mas a lei, com escopo protetivo, proibia, entre outros, o trabalho feminino em condições insalubres, a realização de horas extras e o trabalho noturno.

Em seus estudos, LOPES (2006, p. 410), lançando os olhos por trás destes aspectos iniciais aparentes, constata residir aí uma falsa benignidade porque na mesma condição feminina o trabalho do homem também estava sendo sobre explorado sem se pensar nas mesmas medidas protetivas, o que demonstra que o proteger nada mais era do que recordar o verdadeiro lugar da mulher na sociedade de então (em casa, cuidando da família).

Até este período era próprio da mulher cuidar dos afazeres domésticos quando o homem varão exercia o papel provedor. O âmbito de espaço reservado às mulheres era o âmbito privado, eram poucas as mulheres que se dedicavam a uma formação acadêmica porque não se esperava delas o êxito nos espaços públicos, reservados aos homens.

Outro aspecto relevante diz respeito ainda aos resultados de todo este protecionismo que resultava no encarecimento e consequente desinteresse na contratação de mulheres no mercado de trabalho porquanto era necessário pagar o mesmo salário para uma trabalhadora que não poderia realizar horas extras, trabalhar à noite, ou seja, estaria menos disponível do que os homens. Sem contar que estes últimos sentiam-se e sentem-se até hoje intimidados com o aumento da concorrência com as mulheres no mercado de trabalho.

Assim, a equação resultava em menores salários destinados às mulheres.

Em 1988 é promulgada a Carta Constitucional que destacadamente, inova nos seguintes preceitos:

Art. 50 I - homens e mulheres são iguais em direitos e obrigações;

Art. $7^{\circ}, \mathrm{XXX}$ - proibição de salários, de exercício de funções e de critério de admissão por motivo de sexo;

Art. $7^{\circ}$, XVIII - licença à gestante, sem prejuízo do emprego e do salário, com a duração de 120 dias; 
Art. 201, III - seguro-maternidade;

Art. 10, II, b ADCT - garantia de emprego;

Art. $7^{\circ}, \mathrm{XX}$ - proteção do mercado de trabalho da mulher, mediante incentivos.

A carga contida nos dispositivos referidos é de cunho nitidamente antidiscriminatório, podendo-se afirmar que o intuito do legislador constituinte foi, entre outros, o de efetivamente suprimir toda forma de discriminação de gênero, alçando a mulher a um status de plena capacidade identificando-a ao homem. Porém, para que fosse possível a eficácia plena das disposições legais acima mencionadas, foi necessário revogar alguns dispositivos até então vigentes na Consolidação das Leis do Trabalho - CLT que data de 1943. DELGADO (2002, p. 782) analisa este confronto:

A lei n. 7.885/89, editada meses após a nova Carta, procurou adequar a CLT ao comando antidiscriminatório constitucional. Assim, revogou preceitos que autorizavam a interferência marital ou paterna no contrato empregatício da mulher adulta (antigo art. 446, CLT), revogando, ainda, parte expressiva do capítulo celetista que tratava da "proteção ao trabalho da mulher" (como dispositivos que exigiam atestados médicos especiais da mulher e lhe restringiam a prestação de certos tipos de trabalho: antigos artigos 374/375, 378 a 380 e 387 da CLT, por exemplo).

Assim, resta evidente que o intento da Carta Constitucional de 1988 foi o de mitigar toda forma de discriminação e, em especial no tocante à discriminação de gênero, criando uma igualdade de tratamento entre homens e mulheres.

O parágrafo $5^{\circ}$ do artigo 226, o qual proclama que "os direitos e deveres referentes à sociedade conjugal são exercidos igualmente pelo homem e pela mulher”, também não deixa dúvidas quanto à importância que a Constituição Federal de 1988 conferiu ao princípio da igualdade entre homens e mulheres.

Não foi só a Constituição de 1988 que buscou dar um tratamento isonômico entre homens e mulheres no âmbito familiar, o novo Código Civil de 2002 também inovou ao por fim a figura consagrada desde o Direito Romano do pater familiae, estabelecendo igualdade entre homens e mulheres nas relações familiares, excluindo, pois a antiga concepção da família patriarcal.

Cabe destacar ainda, como faz LOPES (2002, p. 232), que o Direito Internacional também é pródigo em regras protetivas à condição da mulher, segundo a autora tais instrumentos: "impõe a revogação de toda norma ordinária que seja incompatível com os preceitos dos direitos humanos, dessa forma, 
impõe-se a eliminação de todos os obstáculos decorrentes de uma discriminação hierarquizada com relação ao gênero”.

Principalmente quando a Constituição Federal assegurou às mulheres a estabilidade no emprego desde a concepção até 120 dias após o parto, muitos alarmistas viram aí um inevitável esvaziamento das vagas de trabalho para as mulheres considerando os transtornos que seriam causados à ordem econômica das empresas com o afastamento por tanto tempo da mão de obra feminina. O natural era esperar que os empregadores optassem exclusivamente pela contratação de homens.

Em caráter preventivo editou o legislador a Lei n ${ }^{\circ}$ 9029/95 vedando qualquer prática discriminatória, mas cujo escopo primeiro era efetivamente a proteção do mercado de trabalho à mulher, neste sentido JORGE NETO (2008, p. 1020-1021) traça um panorama dos preceitos da referida lei que consistiram em práticas antidiscriminatórias:

Constituem crime as seguintes práticas discriminatórias: a) a exigência de teste, exame, perícia, laudo, atestado, declaração ou qualquer outro procedimento relativo à esterilização ou a estado de gravidez; b) adoção de quaisquer medidas, de iniciativa do empregador, que configurem: 1) indução ou instigamento à esterilização genética; 2) promoção do controle de natalidade, assim não considerado o oferecimento de serviços aconselhamento ou planejamento familiar, realizados através de instituições públicas ou privadas, submetidas às normas do SUS. A pena: detenção de 1 a 2 anos e multa.

Fica claro o intuito do legislador de criar uma espécie de redoma protetora sobre a questão da estabilidade gestacional, já que, do contrário sem a adoção das medidas mencionadas pelo citado autor, seriam criadas formas de se assegurar apenas contratação de mulheres estéreis ou que não representassem risco gestacional.

Não se pode, porém, deixar de observar que a proteção maior criada em verdade não foi para a mulher, mas sim para a concepção, para o nascituro, porquanto a garantia do emprego à mãe representa a garantia da manutenção financeira da criança que está por vir, principalmente na realidade brasileira que, como se demonstrará adiante, é de inúmeras famílias sustentadas por mulheres.

Os doutrinadores trabalhistas como DELGADO (2002), MARTINS (2004), BARROS (2005), só para citar alguns, são quase que unânimes em 
dispor que atualmente, as únicas circunstâncias que justificam a diferenciação entre homens e mulheres têm a ver com a condição física da mulher (emprego da força muscular) e a maternidade, salvo isto, nenhuma outra razão poderia justificar a diferenciação de tratamento entre homens e mulheres.

Mesmo em relação a tais reservas consideradas razoáveis pela maior parte da doutrina é conveniente fazer uma análise criteriosa como faz LOPES (2002, p. 420) para quem:

Deve-se tomar todo o cuidado ao subtrair da "natureza” a justificação para postulados jurídicos, principalmente porque o ser humano é uma mistura indissociável de biologia e cultura. A inferiorização da mulher sempre se apoiou em discursos pretensamente fundados na natureza. A medicina em muito contribuiu para legitimar tais discursos, apoiando-os em também pretensa "cientificidade".

Com razão a autora porquanto até pouco tempo a maternidade era vista como um estado de quase incapacidade, já que a mulher grávida tinha restrições de ação de quase toda ordem e, hoje em dia, salvo nos casos de risco gestacional, já não se coíbe a gestante de práticas esportivas e vida normal, o que implica em trabalho normal, produção normal.

Algumas vezes são as próprias mulheres que criam para si mesmas restrições que resultam em preconceitos que não se justificam numa "cientificidade" efetiva, porquanto se tomarmos como exemplo uma comunidade mais primitiva, como as sociedades indígenas, não há restrições físicas às gestantes como vemos em alguns casos em nossa sociedade.

É possível dimensionar, portanto, que o postulado da igualdade entre homens e mulheres recepcionado pela Constituição Federal de 1988 é pleno, as demais restrições que são feitas pelo ordenamento jurídico dizem respeito apenas a proteção à maternidade que a par de ser uma proteção à mulher é acima de tudo um mecanismo de proteção ao nascituro.

\section{O DIREITO FUNDAMENTAL À IGUALDADE DE TRATAMENTO - ANÃO DISCRIMINAÇÃO}

Partindo, pois, do pressuposto que a igualdade constitucional é plena, necessário verificar sua dimensão nas relações jurídicas jus trabalhistas.

Tanto na Constituição Federal, como já se disse acima, quanto no ordenamento jurídico trabalhista existe a previsão legal contra a discriminação. Na Constituição nos artigos $3^{\circ}, 5^{\circ}$ e $7^{\circ}$ e, artigo $3^{\circ}$, parágrafo único, $5^{\circ}$ e $6^{\circ}$ da CLT. 
Dessa forma a Constituição Federal trouxe um sistema abrangente de proteção contra a discriminação sendo tal proteção alçada a objetivo fundamental da República que visa a promoção do bem-estar de todos, sem preconceitos de origem, raça, sexo, cor, idade e quaisquer outras formas de discriminação.

O renomado autor BELTRAN (2002, p. 204) centra o direito de não sofrer discriminação como um postulado da igualdade de todos os seres humanos.

O princípio da igualdade transmite a ideia de repulsa a toda forma de discriminação, já que discriminação pressupõe desigualdade, muito embora não se possa pensar em eliminação total, já que há momentos em que esta se faz necessária para restabelecer justamente a ideia de justiça. A discriminação que se busca superar é justamente aquela que se mostra arbitrária e não leva em consideração as circunstâncias e padrões.

Na lição de BARROS (2005, p. 104),

[...[ a ideia de pessoa é incompatível com a desigualdade entre elas. E sobre a discriminação situa: é a mais expressiva manifestação do princípio da igualdade cujo reconhecimento, como valor constitucional, inspira o ordenamento jurídico no seu conjunto.

Não se pode, imaginar um Estado que se diz democrático em que seja admissível a existência de condições discriminatórias, seja de que tipo for e, no caso das mulheres, por mais que tenham sido obtidas inúmeras conquistas legais no sentido de se mitigar as práticas discriminatórias, ainda que envolvidas pelo manto de uma proteção mendaz, ainda se constata no ambiente de trabalho uma disparidade de tratamento em relação aos homens.

Medidas contra discriminação e igualdade de tratamento são conquistas recentes das mulheres, todavia, é certo que justamente por se tratar de uma situação recente ainda não se encontra consolidada, havendo inúmeras situações em que a mulher ainda sofre preconceitos e limitações.

Tanto discriminação como igualdade são postulados que podem ser alterados conforme a situação concreta em que se verificam e, nisso podem ter conceitos diversos conforme a construção conceitual dos fatos:

A discriminação no trabalho ganha novos tipos à medida que são estudadas e descobertas novas formas de trabalho no mundo contemporâneo. A discriminação vertical ocorre quando o empregador, com poder de comando sobre o empregado, o impede de ascender profissionalmente por algum motivo, já a discriminação horizontal manifesta-se através de diferenças entre empregados, o que se registra mais claramente nos cargos ocupados por negros e mulheres, com salários diferenciados. 
Considerando especificamente o meio ambiente de trabalho é importante questionar qual é a igualdade pretendida.

Na obra A Virtude Soberana DWORKIN (2012, p. 461), questiona qual é a verdadeira igualdade, uma igualdade de oportunidades ou de resultados? Neste sentido, na busca por igualdade no mercado de trabalho o que pretende a mulher, oportunidades iguais de acesso às vagas de trabalho ou igualdade de êxito, traduzido por bem estar?

Em um primeiro momento, a legislação trabalhista volta-se para uma igualdade no sentido pecuniário, visto que, o art. $5^{\circ}$ da CLT prevê que $A$ todo trabalho de igual valor corresponderá salário igual, sem distinção de sexo.

Nesta mesma linha o art. 373-A da CLT no capítulo referente ao trabalho da mulher, impõe algumas vedações: publicar aviso de emprego no qual haja referência a sexo, idade e outros dados; recusar emprego, promoção ou motivar a dispensa em razão do sexo, idade e outras especificações; considerar o fator sexo, idade, cor e outras situações específicas como variável determinante para remuneração, formação ou ascensão profissional; exigir atestado de comprovação de gravidez ou esterilidade; impedir acesso ou adotar critérios subjetivos para inscrição e aprovação em concursos; proceder a revistas íntimas. Por fim esclarece a possibilidade de serem adotadas medidas temporárias com vistas ao estabelecimento de políticas de igualdade entre homens e mulheres.

A igualdade in casu, abrange, pois, inúmeras condições próprias da relação de emprego, indo muito além da questão financeira, do reconhecimento salarial, abrangendo o reconhecimento social no ambiente de trabalho que se traduz por uma satisfação encontrada pelas mulheres na ascensão profissional ao se alcançar postos que historicamente eram destinados apenas ao sexo masculino.

\section{O MERCADO DE TRABALHO PARA A MULHER EM NÚMEROS}

Nos dados analisados neste artigo é possível constatar que a mulher está cada vez mais alicerçando sua posição no mercado de trabalho, porém, as condições de tratamento no ambiente de trabalho ainda permanecem diferentes, a desejada igualdade ainda é limitada, o que é possível se analisar em números.

A participação das mulheres no mercado de trabalho é uma realidade crescente tanto no mercado brasileiro como no mundo todo, salvo, obviamente os países cuja cultura religiosa restringe a participação feminina em qualquer 
área profissional. A realidade demonstra inclusive uma prevalência da mão de obra feminina engrossando as fileiras tanto do mercado formal como informal de trabalho.

O fluxo de entrada e participação das mulheres no mercado de trabalho na análise de MADALOZZO (2008, p. 15) foi intensificado nas economias ocidentais a partir da década de 50 do século passado.

Ainda segunda a autora nos Estados Unidos, a participação das mulheres no mercado de trabalho aumentou de aproximadamente 34\% no início da década de 50 para 60\% no final do século passado. Para o Brasil, na década de 70, a participação ainda era bastante baixa, em torno de 18\%. Em 2002, a participação das mulheres no mercado de trabalho já atingia os 50\%, segundo dados do IBGE. Ao mesmo tempo, a diferença de salários entre homens e mulheres, conforme esperado, diminuiu drasticamente. No Brasil, ela passou de $50 \%$ no início da década de 90 para menos de 30\% no início dos anos 2000.

Na Europa, embora esta diferença seja bem inferior à verificada no Brasil, de aproximadamente 15\%, desde 2003 ela está estável (European Commission, 2008). Entretanto, quando analisamos o perfil de remuneração de homens e mulheres com maior nível de educação, esta diferença é mais persistente e sinaliza também a pouca representação de mulheres em cargos mais elevados nas empresas.

Em estudo do IBGE (2008) específico sobre o tema da mulher no mercado de trabalho tem-se alguns dados no ano de 2008, informando que conforme a pesquisa Mensal de Emprego nesta época haviam 9,4 milhões de mulheres trabalhando nas seis regiões metropolitanas de abrangência da pesquisa. Este número significava $43,1 \%$ das mulheres com 10 anos ou mais de idade. Em 2003 esta proporção era de 40,1\%. No entanto, mesmo sendo maioria na população total e a despeito do crescimento no seu nível de ocupação, elas ainda eram minoria no mercado de trabalho.

Nas seis regiões metropolitanas, elas lideravam o ranking da desocupação (1,0 milhão). Considerando o total de desocupados das seis regiões, as mulheres representavam $57,7 \%$, enquanto que entre os homens esse contingente é de 779 mil, 42,3\%. No que se refere à forma de inserção no mercado de trabalho, elas também se encontravam em situação menos favorável, não sendo atingindo o percentual de 40\% de mulheres trabalhando com carteira de trabalho assinada; já entre os homens esta proporção ficou próxima de 50,0\%. Na contribuição para previdência o quadro também era desigual. 
Mais de um terço das mulheres (37,0\%) não contribuem para previdência, enquanto o percentual de homens não contribuintes não atingia um terço.

A jornada de trabalho delas era de 40 horas semanais em média, e recebiam, habitualmente, $\mathrm{R} \$ 956,80$ por mês. Esse rendimento correspondia a $71,3 \%$ do rendimento dos homens.

Outro dado que merece destaque é o fato de que neste cenário total relativo ao número de mulheres que trabalham grande parte ainda fica situada no âmbito do emprego doméstico, onde $94,7 \%$ são mulheres e apenas 5,3\% são homens, conforme dados do IBGE.

Já o Ministério do Trabalho (MTE - 2015) em dados mais recentes, informa em seu sítio eletrônico a evolução do trabalho feminino:

O crescimento do público feminino no mercado de trabalho é evidenciado pelos dados da última Relação Anual de Informações Sociais (RAIS 2013) do Ministério do Trabalho e Emprego. Num recorte por gênero, os dados evidenciam que em 2013 o nível de emprego da mão-de-obra feminina cresceu $3,91 \%$, ante um aumento de 2,57\% para os homens, uma diferença de 1,34 pontos percentuais. Os dados revelam ainda uma continuidade no processo de elevação da participação das mulheres no mercado trabalho formal, que passou de 42,47\% em 2012 para 42,79\% em 2013.

No tocante, porém, aos pisos salariais, através da mesma pesquisa utilizando-se as RAIS, é possível verificar que as mulheres continuam auferindo um ganho médio inferior ao dos homens, sendo que, em 2013 esse valor para as mulheres chegou a $\mathrm{R} \$ 2.018,48$ contra $\mathrm{R} \$ 2.451,20$ para os homens, muito embora, esta pesquisa demonstre que houve um aumento da taxa de elevação salarial das mulheres em confronto com os homens. As mulheres obtiveram uma taxa de aumento salarial de $3,34 \%$ enquanto os homens ficaram em $3,18 \%$.

Salvo este último dado, quando o contexto é mercado de trabalho, a maioria dos indicadores apresentados mostra, pois, a mulher, em condições menos adequadas que a dos homens. Entretanto, estas estatísticas não são explicadas pela escolaridade, visto que, neste cenário, elas ocupam posição de destaque. Aproximadamente 60,0\% das mulheres ocupadas tinham, pelo menos, a escolaridade referente ao ensino médio. Todavia, observou-se que as diferenças entre os rendimentos de homens e de mulheres eram maiores entre os mais escolarizados. A remuneração das mulheres com curso superior era, em média, $40 \%$ inferior a dos homens. 
Ainda no tocante a esta diferença salarial, elucidativa é a tabela fornecida pelo Ministério do Trabalho (MTE 2015) que diferencia o comportamento salarial por gênero e grau de instrução:

SALÁRIO MÉDIO REAL (*) DE ADMISSÃO

COMPORTAMENTO POR GRAU DE INSTRUÇÃO E GÊNERO - BRASIL - JAN A DEZ (2012 E 2011)

\begin{tabular}{|c|c|c|c|c|c|c|c|c|c|c|c|}
\hline \multirow[t]{2}{*}{ Grau Instrução } & \multicolumn{3}{|c|}{2012 (JAN A DEZ) } & \multicolumn{3}{|c|}{2011 (JAN A DEZ) } & \multicolumn{3}{|c|}{ Variação Relativa } & \multicolumn{2}{|c|}{$\begin{array}{c}\text { Relação Salários } \\
\text { Feminino/Masculino }\end{array}$} \\
\hline & \begin{tabular}{|l|} 
Masculino \\
\end{tabular} & Feminino & Total & Masculino & Feminino & Total & Masculino & Feminino & Total & 2012 & 2011 \\
\hline Analfabeto & 772,21 & 717,14 & 763,36 & 707,84 & 669,96 & 701,98 & 9,09 & 7,04 & 8,74 & 92,87 & 94,65 \\
\hline Até $5^{a}$ & 852,18 & 715,99 & 827,89 & 797,37 & 672,67 & 776,03 & 6,87 & 6,44 & 6,68 & 84,02 & 84,36 \\
\hline $\begin{array}{l}\text { Incompleto } \\
5^{2} \text { Completo }\end{array}$ & 893,36 & 730,71 & 856,84 & 844,04 & 682,76 & 808,56 & 5,84 & 7,02 & 5,97 & 81,79 & 80,89 \\
\hline $\begin{array}{l}\text { Fa a } 9^{a} \\
\text { Fundamental }\end{array}$ & 895,61 & 722,62 & 852,4 & 847,35 & 681,41 & 807,41 & 5,7 & 6,05 & 5,57 & 80,68 & 80,42 \\
\hline $\begin{array}{l}\text { Fundamental } \\
\text { Completo }\end{array}$ & 944,69 & 751,79 & 889,77 & 892,5 & 706,14 & 840,49 & 5,85 & 6,46 & 5,86 & 79,58 & 79,12 \\
\hline $\begin{array}{l}\text { Médio } \\
\text { Incompleto }\end{array}$ & 859,58 & 705,35 & 806,24 & 817,98 & 668,7 & 767,66 & 5,09 & 5,48 & 5,03 & 82,06 & 81,75 \\
\hline $\begin{array}{l}\text { Médio } \\
\text { Completo }\end{array}$ & $1.013,44$ & 817 & 930,38 & 971,6 & 773,17 & 887,84 & 4,31 & 5,67 & 4,79 & 80,62 & 79,58 \\
\hline $\begin{array}{l}\text { Superior } \\
\text { Incompleto }\end{array}$ & $1.349,31$ & $1.065,13$ & $1.196,85$ & $1.351,26$ & $1.044,81$ & $1.190,26$ & $-0,14$ & 1,94 & 0,55 & 78,94 & 77,32 \\
\hline $\begin{array}{l}\text { Superior } \\
\text { Completo }\end{array}$ & $3.276,48$ & $2.023,97$ & $2.577,66$ & $3.280,66$ & $1.997,57$ & $2.569,77$ & $-0,13$ & 1,32 & 0,31 & 61,77 & 60,89 \\
\hline Total & $1.067,66$ & 917,87 & $1.011,77$ & $1.019,34$ & 874,63 & 966,45 & 4,74 & 4,94 & 4,69 & 85,97 & 85,8 \\
\hline
\end{tabular}

Estes dados demonstram claramente que o mercado de trabalho ainda comporta uma divisão sexista e uma oposição entre o masculino e o feminino que persiste historicamente e, muito embora, tenha havido uma significativa elevação do nível de qualificação escolar e universitário feminino é visível que esta condição não abre uma perspectiva de carreira porque ainda há uma marcante diferença salarial entre homens e mulheres sem contar que há um véu sobre o mercado de trabalho doméstico onde a grande maioria ainda é composta por mulheres.

\section{O TETO DE VIDRO}

Considerando, pois, esta linha divisória que demarca os limites da mulher no mercado de trabalho e, na reflexão sobre a busca de uma efetiva igualdade de tratamento das mulheres no ambiente de trabalho esbarra-se no fenômeno denominado “teto de vidro” que é uma limitação à ascensão feminina em níveis verticais da hierarquia organizacional.

Na definição de STEIL (1997, p. 62) trata-se de "uma barreira que, de tão sutil, é transparente, mas suficientemente forte para impossibilitar a ascensão de mulheres a níveis altos da hierarquia organizacional”. 
Tal fenômeno é a denominação da discriminação vertical em que se verifica uma limitação à ascensão feminina aos cargos de maior remuneração.

Vencidas as barreiras iniciais que criavam empecilhos à contratação da mão de obra feminina, pois como se viu acima, a própria lei criou discriminações sob o pretexto de proteger, mas, que ao final impediam o pleno emprego para as mulheres, hoje a barreira é outra. A mulher, em países democráticos, tem acesso a quase toda forma de trabalho remunerado, porém, não tem as mesmas possibilidades de êxito ou, nos dizeres de DWORKIN (2012, p. 15), a uma igualdade genuína alicerçada em uma questão de satisfação.

Não é tarefa fácil identificar os níveis de satisfação das mulheres no acomodamento inicial com cargos inferiores, porém, é possível medir a satisfação através dos resultados financeiros, neste sentido, SANTOS e RIBEIRO (2006, p. 2) esclarecem:

[...] os diferenciais aumentam ao longo das distribuições de rendimentos, sendo este efeito apelidado em vários países de glass ceiling ou teto de vidro. Este teto seria uma barreira invisível que impediria o acesso de mulheres a postos e ocupações de melhores rendimentos. Recentemente, com o lançamento da Síntese de Indicadores Sociais de 2005 pelo IBGE em abril de 2005, foi noticiado na imprensa que os diferenciais (não controlados) de rendimentos por gênero aumentam ao longo dos decis (sic.) de renda e aumentam por grupo de anos de estudo. Naquela publicação pode-se ver que enquanto as mulheres, em media, recebem $84 \%$ do rendimento dos homens, este diferencial aumenta de $80,8 \%$ para pessoas com até 4 anos de estudo, para $61,6 \%$ para pessoas com 12 anos ou mais de estudo.

Por mais que o ordenamento jurídico, em especial o texto constitucional, tenha formalmente assegurado uma igualdade de tratamento a realidade aponta para a existência de uma quantidade ainda pequena de mulheres em cargos de maior projeção, seja em termos de remuneração como poder, isto tanto no ambiente público quanto no privado.

Pode-se observar também que em países considerados desenvolvidos este é um fenômeno presente. A autora ROCHA (2006, p. 105), traz em sua tese, um relato de uma cidadã alemã, altamente graduada, que exemplifica nitidamente esta situação limítrofe para as mulheres:

Como estudante de graduação e de pós-graduação [em engenharia], nível doutorado, nunca tive problema algum. Quando trabalhei em uma companhia como engenheira, nunca houve qualquer problema em relação às questões 
relacionais de gênero. Então, cheguei naquilo que os/as americanos/as chamam de glass ceiling. Era uma firma canadense de produção de alumínio. A questão era se eu poderia ser promovida a gerente de fábrica, onde trabalhavam quinhentos homens, ou, pelo menos, que a maioria destes trabalhadores era homens. A diretoria disse que não seria bom ter uma mulher como gerente de fábrica, que não seria o emprego certo para uma mulher. Não era o fato de que houve dúvidas quanto a minha competência.

Os cursos superiores, cursos de graduação e pós-graduação, contam com um número cada vez maior de mulheres, talvez este número hoje possa até mesmo ser superior ao dos homens, não havendo estudos sérios a este respeito, porém, ainda que mais qualificadas que os homens ainda são discriminadas no alcance dos cargos de maior relevância na carreira.

Em tese de doutorado que analisa as questões de gênero e, principalmente a limitação do acesso das mulheres aos níveis hierárquicos superiores, a autora ROCHA (2006, p. 104), nos mostra como surgiu o estudo sobre este fenômeno:

O fenômeno do glass ceiling não é, de modo algum, recente e já foi objeto de atenção e reflexões de organizações e pesquisadoras/es (principalmente norteamericanos/as) preocupadas/os com a paridade de gênero nas diversas esferas da vida. Este foi, inclusive, um dos itens discutidos em mesa-redonda ocorrida em Lisboa no ano de 1985, organizada pela UNESCO e pela Federação Internacional de Mulheres Universitárias. O tema da mesaredonda foi: "A responsabilidade das mulheres no desempenho de sua carreira e no ensino superior”. O encontro resultou num documento contendo sugestões e recomendações para problemas levantados pelas/ os participantes. Dentre estas, está a questão do "teto de vidro", nos seguintes termos: "Nos níveis profissionais de tomada de decisões, as mulheres estão quase sempre ausentes; foi mencionado o fenômeno do glass ceiling, ou seja, de modo geral, as mulheres conseguem chegar ao 2.0 escalão, mas não ao primeiro.

Mas o traço relevante do chamado "teto de vidro" ou de cristal, reside justamente no fato de que se trata de uma metáfora interessante porque remete a uma barreira de vidro, ou seja, é um empecilho que pode ser destruído porque é tênue "é mais fácil se estilhaçar um vidro, rompendo-o enquanto barreira, e adentrar outros espaços, do que bater de encontro a estruturas extremamente rígidas, como o mármore ou o granito, por exemplo,” (ROCHA, 2006, p. 105). 
O teto de vidro baseia-se, pois, na constatação de que a divisão social dos espaços masculinos e femininos é assimétrica e hierarquizada, onde o masculino domina e para adequação das mulheres há uma abrangência do feminino pelo masculino e, neste aspecto, para poder alcançar um lugar neste mundo estruturado pela ordem masculina a mulher se submete aos ditames desta ordem dos sexos em que para ser considerada apta ao exercício de cargos de autoridade e poder, é necessário assimilar o masculino.

A mulher não se pode conformar com esta limitação, não pode se conformar em manter-se sob este teto, é necessário quebrar esta barreira e ascender profissionalmente na mesma medida que é assegurada aos homens.

Não basta tentar fazer transpor a barreira através de uma projeção de imagem, o que seria possível porque o vidro é material transparente, porque neste nível a mulher estaria apenas lançando suas ideias, seu trabalho para além dela mesma por outros meios que não pelo seu mérito o que só pode ocorrer quando o vidro for quebrado.

Esta situação já se verificou na história quando mulheres utilizaram-se de alcunhas e personagens masculinas para poderem apresentar seus projetos, suas obras ao mundo masculino e receberem a aceitação que seria esperada a um trabalho masculino.

Não é isto porém que significa superar a discriminação, não é isto que significa alcançar a esperada igualdade, cabe ainda, mais uma vez o esclarecimento preciso de ROCHA (2006,p. 107):

Neste caso, a "passagem” pelo teto de vidro, devido a sua permeabilidade, é apenas simbólica, visto que não se consegue romper as hierarquias estruturais, funcionais e de poder. É então que há riscos ao se fazer concessões, visto que se estabelece a constatação de que ou se quebra, rompe estilhaça o teto de vidro, ou não se consegue mudar nada. Desta maneira, a própria concepção teórica de que o telhado de vidro é permeável, poderia implicar em valores direcionados a “ajustes” por parte das mulheres, e não implosão deste teto. Neste sentido, não se deve realmente fazer concessões teóricas.

Mas como é possível romper esta barreira?

Teriam sido os preceitos constitucionais e infraconstitucionais suficientes para assegurar uma igualdade de tratamento entre homens e mulheres?

Pelos números apresentados pelo IBGE e pelo próprio fenômeno do "Teto de Vidro” fica claro que não, “não basta à positivação ou a constitucionalização 
dos direitos humanos da mulher, garantidores da dignidade, é preciso uma forte conscientização social, bem como uma postura governamental mais comprometida”, sustenta ROCHA (2006, p. 109).

Se o postulado constitucional de igualdade de gênero já se mostrou insuficiente entende-se que medida eficiente a ser ponderada para dar efetividade a este direito fundamental é a adoção de ações afirmativas no sentido de coibir a adoção de critérios de promoção que sejam restritivos ao alcance das mulheres.

Em igualdade de condições, teria que haver justificação para que o empregador pudesse preterir a mulher na ascensão profissional em carreiras de acesso vertical.

Não basta elevar a direito fundamental a igualdade é necessário instrumentalizá-la, neste sentido, seria possível adotar medidas para se impor aos empresários e empregadores de modo geral, inclusive no âmbito do Direito Público, uma equivalência de promoções para homens e mulheres, uma equivalência numérica, admitindo-se promoções de homens e mulheres em mesmo número, promovendo uma efetiva igualdade de oportunidades.

Ainda que bastante criticada nos dias atuais, a adoção de ações afirmativas seria uma forma de se promover uma discriminação positiva objetivando uma atitude proativa em favor da igualdade de tratamento entre homens e mulheres no mercado de trabalho assegurando uma real igualdade de oportunidades e sucesso profissional.

Neste sentido há que se coibir medidas discriminatórias no alcance de cargos elevados quando na disputa estiverem mulheres capacitadas sendo preteridas por uma simples condição de gênero, podendo se utilizar de incentivos fiscais ou selos sociais para empresas que tenham número expressivo de mulheres em cargos de confiança em igualdade de condições com os homens.

No tocante às próprias mulheres é preciso romper as barreiras culturais que as levam a se segregar em guetos masculinos quando alçam ao poder atuando tão discriminatoriamente como os homens em idênticas condições, porque acabam assumindo que para manter-se na hierarquia empresarial é necessário agir como homem, porquanto ao assim proceder apenas ultrapassam ilusoriamente os limites da barreira de vidro, fazendo uma imagem deturpada de si mesmas não se reconhecendo como mulheres aptas a alcançar o sucesso profissional.

Visto isto, é possível definir o "teto de vidro” como um simbolismo representativo do reconhecimento de que nossa ambição tem limites e estes limites ainda são impostos por uma sociedade machista que concede por um lado e restringe por outro. 


\section{CONSIDERAÇÕES FINAIS}

Ainda que a legislação e, em especial a Constituição Federal de 1988 tenha inovado no sentido de coibir toda forma de discriminação, assegurando que homens e mulheres são iguais em direitos e obrigações ainda se verificam diversos pontos que revelam a discriminação contra a mulher no ambiente laboral.

Persistem ainda as discriminações que se revelam protetivas à questão biomórfica que, todavia, não parecem se justificar já que as mesmas condições que são penosas ou insalubres para as mulheres também o são para os homens. No conceito de medidas discriminatórias positivas o que parece razoável é ainda a proteção a maternidade, muito embora neste aspecto não se trate de uma medida de proteção à mulher propriamente mas antes de proteção ao nascituro e à criança.

Fora esta questão, não se justifica qualquer outra forma de tratamento desigual às mulheres, todavia, os números apresentados na pesquisa demonstram que muito embora as mulheres estejam avançando numericamente no mercado de trabalho não logram alcançar patamares justos em termos de êxito na carreira.

É como dizer "sim nós aceitamos vocês nos meios produtivos, todavia, vamos continuar mantendo o controle do jogo”.

Neste aspecto a legislação não se mostra suficiente para assegurar o pleno emprego porque somente o seria aquele que fosse livre para levar a mulher a alcançar a isonomia na carreira profissional, na satisfação pessoal e econômica.

Considerando a insuficiência da legislação seria possível pensar em ações afirmativas consistentes em incentivos fiscais para empresas que mantenham número expressivo de empregadas em cargos de níveis hierarquicamente mais elevados, concessão de selos sociais de respeito à mulher nestas mesmas condições.

Por outro lado, é necessário reconhecer que por diversas vezes são as próprias mulheres que renegam o gênero, execrando movimentos feministas como se com isso alcançassem o universo masculino e suas conquistas.

Como em todos os movimentos sociais é necessário engajar-se, incumbe às mulheres enxergar estas limitações e vencer esta barreira de modo efetivo, não basta crer que já se alcançou o possível porque isto é ilusório. Se necessário é preciso manter o movimento feminista na arena social e política, cumprindo seu papel de plena cidadania cobrando a adoção de ações afirmativas como meio eficaz de combate à esta nova forma de discriminação velada, buscando, com isso, uma igualdade no campo material. 


\section{REFERÊNCIAS}

ALAMBERT, Zuleika. A mulher na história. A história da mulher. Fundação Astrogildo Pereira/FAP; Abaré. 2004.

BARROS, Alice Monteiro de. Curso de Direito do Trabalho. São Paulo, Editora LTR, 2005.

BELTRAN, Ari Possidonio. Direito do Trabalho e Direitos

Fundamentais. Editora LTR, São Paulo, 2002.

BRASIL, Ministério do Trabalho e Emprego in, http://portal.mte.gov.br/ imprensa/rais-e-caged-indicam-crescimento-da-participacao-da-mulher-nomercado-de-trabalho.htm

BRUSCHINI, Cristina e LOMBARDI, Maria Rosa. A Bipolaridade do Trabalho Feminino no Brasil Contemporâneo. In Cadernos de Pesquisa, $n^{0}$ 110. São Paulo: Fundação Carlos Chagas, 2000. p. 67-104.

DELGADO, Maurício Godinho. Curso de Direito do Trabalho. São Paulo, LTR, 2010.

DWORKIN, Ronald. A virtude Soberana - a teoria e a prática da igualdade. Martins Fontes, São Paulo. 2012.

IBGE. Suplemento Mulher - algumas características da inserção da mulher no mercado de trabalho. Rio de Janeiro, 2008.

LOPES, Aline Luciane. A mulher e a construção da cidadania na perspectiva dos direitos humanos. Revista Argumenta, $n^{0} 15$, p. 223 a 237.

LOPES, Cristiane Maria Sbalqueiro. Direito do trabalho da mulher da proteção à promoção, 2006, in http://www.scielo.br/pdf/cpa/n26/30398.pdf

MADALOZZO, Regina. Martins, Sérgio Ricardo. Shiratori, Ludmila. Participação no mercado de trabalho e no trabalho doméstico. 
Homens e Mulheres tem condições iguais? São Paulo, INSPER/ IBMEC, 2008.

MARTINS. Sérgio Pinto. Direito do Trabalho.21ed.São Paulo. Editora Atlas, 2004.

MEAD, Margareth. Antropologia. Revista Veja, 22 de novembro de 1978, Edição n ${ }^{0}$ 533, in http://www.oexplorador.com.br/site/ver.php?codigo=15260

JORGE NETO, Francisco Ferreira; CAVALCANTE, Jouberto de Quadros Pessoa. Direito do Trabalho, $4^{\mathrm{a}}$ edição. Editora Lumen Juris, Rio de Janeiro, 2008.

ROCHA, Cristina Tavares da Costa. Gênero em ação. Rompendo o Teto de Vidro? 2006, (Tese Doutorado) Ciências Humanas, Universidade Federal de Santa Catarina;

SANTOS, Renato Vale, RIBEIRO, Eduardo Pontual. Diferenciais de Rendimentos entre Homens e Mulheres no Brasil revisitado: explorando o “Teto de Vidro”. Disponível em: http://www.ie.ufrj.br/ eventos/seminarios/pesquisa/texto06_05_02.pdf

STEIL, Andrea V., Organizações de gênero e posição hierárquica compreendendo o fenômeno do teto de vidro, Revista de Administração, São Paulo, v. 32, p. 62-69, julho/setembro 1997.

Artigo recebido em: 12/05/2015 Aprovado para publicação em: 19/08/2015

Como citar: BERNARDI, Renato. NEVES, Raquel Cristina. As garantias constitucionais à igualdade de gênero e a realidade do "teto de vidro" para a mulher trabalhadora. Revista do Direito Público. Londrina, v.10, n.2, p.167-186, mai./ago. 2015. DOI: 10.5433/1980-511X.2015v10n2p167. 